CORRECTION

https://doi.org/10.1038/s41586-018-0168-1

\title{
Publisher Correction: Synthesis, structure and reaction chemistry of a nucleophilic aluminyl anion
}

Jamie Hicks, Petra Vasko, Jose M. Goicoechea \&

Simon Aldridge

Correction to: Nature https://doi.org/10.1038/s41586-018-0037-y,

published online 16 April 2018.

In Fig. 1 of this Letter, the hydrogen $(\mathrm{H})$ atoms attached to each of the two nitrogen $(\mathrm{N})$ atoms in the chemical structure of $(\mathrm{NON}) \mathrm{H}_{2}$ were inadvertently missing. The original figure has been corrected online. 